\title{
ESTRATÉGIAS REPRODUTIVAS DE BONNETIA STRICTA (BONNETIACEAE) PRESENTES NA MATA CILIAR DO RIO LENÇÓIS, CHAPADA DIAMANTINA, BAHIA.
}

\author{
Thayse Moreira Costa ${ }^{1}$; Lígia Silveira Funch ${ }^{2}$ \\ ${ }^{1}$ Bolsista de Iniciação Cientifica, CNPq / Universidade Estadual de Feira de Santana. \\ Email: thayse.costa@outlook.com \\ ${ }^{2}$ Orientadora do departamento de Ciências Biológicas, Universidade Estadual de Feira de Santana. Av. Transnordestina, s/n, \\ Novo Horizonte, 44036-900, Feira de Santana, BA. Email:ligiafunch@yahoo.com
}

\section{PALAVRAS-CHAVE: autocompatibilidade; sistema reprodutivo; dispersão}

\section{INTRODUÇÃO}

Bonnetiaceae pertence à ordem Malpighiales, incluindo cerca de 30 espécies neotropicais (Weitzman, 2005). Apenas duas espécies ocorrem no Brasil, Bonnetia stricta (Nees) Nees \& Mart e Bonnetia roraimae Oliv. (Bittrich, 2015). B. stricta é uma planta arbustivo-arbórea encontrada nos domínios fitogeográfigos do Cerrado e Mata Atlântica, na Bahia, Espírito Santo e Rio de Janeiro (Costa et al. 2010). Na Bahia, B. stricta tem distribuição disjunta entre os campos rupestres e matas ciliares da Chapada Diamantina e restingas do litoral (Harley 1995). O sistema reprodutivo inclui diferentes sistemas de cruzamento, sendo autógamos, alógamos e mistos (Radford et al. 1974). Segundo Ferreira \& Borghetti (2004), a dispersão de sementes consiste na liberação dos diásporos e seu deslocamento para sítios de colonização da planta. A germinação de sementes atua como pressão seletiva sobre os padrões reprodutivos das espécies favorecendo a dispersão de sementes na época mais favorável a este processo (Rathcke \& Lacey 1985). Estudos que tragam informações sobre essas variadas abordagens ainda são escassos sobre espécies tropicais. Assim o presente estudo traz resultados de sistema reprodutivo, dispersão e germinação de B. stricta na mata ciliar do rio Lençóis, Chapada Diamantina, Bahia, discutindo nossos resultados prévios de fenologia, biologia floral e visitantes florais a fim de compreender a estratégia reprodutiva desta espécie.

\section{METODOLOGIA}

Para o estudo dos sistemas reprodutivos, foram feitos cinco testes de polinização proposto por Dafni et al. (2005). Em todos os testes, botões florais foram ensacados (saco de voil). Esta estratégia foi determinada com a utilização de 20 flores por tratamento de polinização e 50 flores como tratamento-controle (sem ensacamento) no período reprodutivo da espécie. Após a realização dos testes, as flores polinizadas foram deixadas para a observação da formação de frutos. Para a análise da viabilidade de pólen foi utilizada a metodologia proposta por Dafni et al. (1992).

A descrição do diásporo de B. stricta se baseou nos caracteres de tamanho, forma, cor e consistência da testa, embrião e presença/ausência do endosperma, além da utilização de medidas e ilustrações feitas em câmara clara acoplada a esteromicroscópio. Foram contabilizadas 100 sementes de B. stricta para cada área de estudo, Lençóis e Ituberá. A distribuição normal dos dados foi testada através de Shapiro-Wilk, feito no Past com o valor de significância $\mathrm{p}>0,05$. Para verificar a ocorrência de formação embrionária, foram analisadas 3 mil sementes coletadas em Lençóis adotando critério de presença/ausência de embrião.

O tipo de dispersão foi classificado com base nos caracteres morfológicos e comportamento aerodinâmico apresentado pela semente da espécie estudada, como proposto por Augspurger (1986). Para avaliar o potencial de dispersão da espécie foi adotada a metodologia proposta por Augspurger (1986). Para estimar o peso da semente de B. stricta, foram pesadas 100 sementes em balança analítica, sendo o resultado dividido pela quantidade de sementes e estimado o peso de apenas uma semente. A velocidade do vento foi mensurada utilizando 
anemômetro digital. O tempo e queda foi mensurado com cronometro digital de mão. A altura foi mensurada utilizando fita métrica de tecido. Foram utilizadas 30 sementes as quais foram soltas em alturas distintas de $22 \mathrm{~cm}$ (dentro da balança analítica) e $100 \mathrm{~cm}$.

Para coleta de sementes, os frutos foram ensacados utilizando sacos de voil. Tais sementes foram observadas em placas de Petri e substrato em dois experimentos, o primeiro em fevereiro de 2016 e o segundo em junho de 2016. Os testes de germinação de sementes de $B$. stricta, foram realizados na UEFS no laboratório Flora e Vegetação por meio de: a) contagem de 100 sementes com a verificação aleatória de sementes viáveis e não viáveis; b) esterilização com hipoclorito de sódio a $0,5 \%$; c) placas de Petri com papel germitest umedecido com água destilada. A unidade experimental foi de 25 sementes por placa com quatro repetições. O tempo da germinação foi contabilizado desde o início da germinação até o período necessário para a protrusão da radícula. $\mathrm{O}$ estudo de germinação em substrato utilizou interações significativas entre o substrato e quantidade de água. As sementes foram postas aleatoriamente dentro de pequenos recipientes plásticos e colocadas sobre uma camada uniforme de areia umedecida. A esterilização do substrato foi feita, seguindo a metodologia presente nas Regras para Análise de Sementes (Brasil, 2009).

\section{RESULTADOS E DISCUSSÃO}

Os testes para verificação dos sistemas reprodutivos em B. stricta da mata ciliar do rio Lençóis foram realizados com 50 flores ensacadas para polinização cruzada natural (controle); 6 botões em pré-antese para polinização cruzada induzida (xenogamia); 6 botões em pré-antese para polinização cruzada induzida (geitonogamia); 17 botões em pré-antese para autopolinização espontânea; 15 botões em pré-antese para o teste de autopolinização induzida; 15 botões em pré-antese para o teste de apomixia (agamospermia). A espécie apresentou resultado negativo para autopolinização e apomixia, e resultados positivos para os testes de xenogamia, geitonogamia e autopolinização induzida.

Estudando o sistema reprodutivo de B. stricta em restinga no Rio de Janeiro, Silva \& Barroso (1995) obtiveram resultados negativos para os testes de autopolinização espontânea e apomixia, e resultados positivos para os testes de autopolinização induzida, xenogamia e geitonogamia. Os autores mostraram que $B$. stricta apresenta formação de frutos endogâmicos através de autogamia e geitonogamia, em proporções iguais aos xenogâmicos, sendo por tanto uma espécie autocompatível. Nossos testes confirmam os dados da literatura demonstrando a necessidade de polinização para que as sementes de B. stricta se desenvolvam. Como os botões em pré-antese ensacados e as flores ensacadas sem polinização manual não formaram frutos, nossos dados evidenciam que a espécie necessita de um vetor para que ocorra a transferência de pólen para o estigma. A receptividade estigmática foi verificada desde os botões em antese até o início do processo de fechamento das flores. Os grãos de pólen foram disponibilizados das 06:00 - 14:00h, com 100\% de viabilidade polínica durante todo o ciclo floral. Contudo foi observada uma redução significativa na quantidade de grãos por antera ao longo do dia. Resultados semelhantes são encontrados em espécies tropicais, a exemplo de Senna cana (Leguminosae), espécie arbustivo-arbórea também comum na mata ciliar do rio Lençois, onde há uma redução significativa na quantidade de grãos por antera ao longo dos dias (Souza et al. 2012).

B. stricta apresenta frutos secos, deiscentes do tipo cápsula septicida. As médias de tamanhos (comprimento e largura) de sementes de Lençóis e Ituberá apresentam pouca diferença, com ca. $2,5 \mathrm{~mm}$ e $3,1 \mathrm{~mm}$ para comprimento e $0,47 \mathrm{~mm}$ e $0,46 \mathrm{~mm}$ de largura respectivamente. Apresenta morfologia linear e alongada com peso aproximado de 0,000057 g ou 5,7 x10-5 g. A testa é castanha, lisa, tênue e membranácea. O embrião é hialino, central, oblongo, hipocotiledonar, com ca de 1,0 mm. Não apresenta endosperma. 
Verificando a ocorrência de presença/ausência embrionária, foram analisadas 3 mil sementes, destas, apenas 509 (17\%) apresentavam embrião e as demais 2,491 (83\%) sementes não apresentavam embrião. Silva \& Barroso (1995) analisaram 500 sementes de B. stricta e encontraram 175 (35\%) sem o embrião, 21 (4,2\%) contendo embrião com malformação e as demais 301 sementes $(60,8 \%)$ apresentavam embrião hipocotiledonar característico.

O potencial de dispersão foi testado em laboratório, com velocidade do vento $0,0 \mathrm{~m} / \mathrm{s}$, tendo a semente massa de $5,7 \times 10^{-5}$. Considerando o tempo de queda, a fração de segundo é quase nula, resultando em 1 segundo em alturas distintas como em $22 \mathrm{~cm}$ e $100 \mathrm{~cm}$. De acordo com os resultados encontrados, sendo o peso e o tempo de queda quase nulos não foi necessário a realização dos cálculos do potencial de dispersão proposto por Augspurger (1986). As sementes caracterizadas como pulverulentas são favorecidas pelo seu desenho e leveza para o transporte pelo vento por longas distancias sem cair na superfície.

$\mathrm{O}$ vento é o vetor mais comum de dispersão, sendo os fatores que mais influenciam o seu elevado potencial de dispersão os seguintes: (i) baixa velocidade de queda; (ii) forma do propágulo; (iii) a estrutura da superfície combinada com a altura de liberação das sementes (Tackenberg et al. 2003a apud Poschlod et al. 2005). Além desses, as condições meteorológicas, como a velocidade do vento e a ocorrência de correntes de ar ascendentes, e o tipo de vegetação em que a planta estudada se encontra, por exemplo, comunidades de plantas que ocorrem em áreas abertas, irão favorecer o maior potencial de dispersão anemocórica (Nathan et al. 2002; Tackenberg et al. 2003b apud Poschlod et al. 2005). B. stricta apresenta alto potencial de dispersão pelo vento na de mata ciliar, onde ajusta a alta produção de sementes, pulvurulentas, leves, e seu porte arbustivo-arbóreo para o lançamento destes diásporos em um habitat relativamente aberto, de borda natural.

Bonnetia stricta apresenta germinação epigeal. As sementes não presentam dormência; a germinação inicia após uma semana na placa ou substrato, com formação da plântula após um mês e meio após o plantio em substrato. As sementes coletadas nos anos de 20132014 e 2015 não germinaram, porém, as coletadas em fevereiro de 2016 germinaram verificando que o embrião fica cerca de 6 meses viável. Sementes diminutas como as de B. stricta são comumente relatadas na literatura como sem dormência e de germinação rápida (Poschlod et al. 2005).

\section{CONCLUSÃO}

A sazonalidade na floração e frutificação Bonnetia stricta, o porte arbustivo-arbóreo, a alta produção de diásporos caracterizados como pulvurulentos e leves garantem a espécie um alto potencial de dispersão de suas sementes, as quais podem alcançar longas distâncias. As sementes germinam rapidamente, favorecidas pelas condições favoráveis das chuvas de verão, devido à ausência de dormência, de endosperma e da baixa quantidade de reservas. Nossos resultados mostraram que a combinação dos estudos de fenologia, biologia floral, sistema reprodutivo, dispersão e germinação é um instrumento importante para a compreensão do sucesso reprodutivo das populações de Bonnetia stricta.

\section{REFERENCIAS}

AUGSPURGER, C.K. 1986. Reproductive synchrony of tropical plants: experimental effects of pollinators and seed predators on Hybanthus prunifolius (Violaceae). Ecology 62: 775-778 BRASIL. 2009. Ministério da Agricultura, Pecuária e Abastecimento. Regras para análise de sementes. Ministério da Agricultura, Pecuária e Abastecimento. Secretaria de Defesa Agropecuária. Brasília, DF: Mapa/ACS. 
COSTA, G.M; SÃO-MATEUS, W.M.; OLIVEIRA, R.P \& GIULIETTI, A.M. 2010. Flora da Bahia: Bonnetiaceae. Sitientibus Série Ciências Biológicas 10(1):77

DAFNI, A. 1992. Pollination ecology: a practical approach (the practical approach series). New York, Oxford, University Press.

DAFNI, A.; KEVAN, P.G.; HUSBAND, B.C. 2005. (Ed.). Practical pollination biology. Cambridge: Enviroquest. p. 590

FAEGRI, K., VAN DER PIJL, L. 1979. The Principles of Pollination Ecology. 3 ed. Oxford: Pergamon Press. p. 115-119.

FERREIRA, A. G.; BORGHETTI, F. 2004. Germinação do básico ao aplicado. São Paulo: Artmed Editora S.A., p. 324

HARLEY, R.M. Introduction. 1995.In: B.L. Stannard (ed.). Flora of the Pico das Almas, Chapada Diamantina, Brazil. Kew, Royal Botanic Gardens: 1-40.

LINERA, W. G., MEAVE, J. 2002. Patrones fenológicos. In: Ecologia y conservación de bosques neotropicales (M. R.Guariguata \& G. H. Kattan, eds.). Libro Uníversitario Regional, p. 407-431.

POSCHLOD, P.; TACKENBERG, O.; BONN, S. 2005. Plant dispersal potential and its relation to species frequency and co-existence. In: Maarel, Eddy van der. Vegetation Ecology. Uk: Blackwell Science Ltd. p. 147 - 162.

RADFORD, A.E.; DICKSON, W.C.; MASSEY, J.R.; BELL, C.R. 1974. Vascular plant systematics. Harper \& Row, New York. p. 891

RATHCKE, B. \& LACEY, E.P. 1985. Phenological patterns of terrestrial plants. Annual Review of Ecology and Systematics 16:179-214.

SHELDON, J.C. \& BURROWS, F.M. 1973. The dispersal effectiveness of the achenepappus units of selected Compositae in steady winds with convection. New Phytologist, 72, 665-675

SILVA, A. G. DA; BARROSO, G. M. 1995. A Biologia da Reprodução de Bonnetia stricta (Theaceae). Arq. Jardim Botânico do Rio de Janeiro. Rio de Janeiro. v. 33, n. 2, p. 109-131.

SOUZA, I. M., COUTINHO, K. \& FUNCH, L. S. 2012. Estratégias fenológicas de Senna cana (Nees \& Mart.) H.S. Irwin \& Barneby (Fabaceae: Caesalpinioideae) como mecanismo eficiente para atração de polinizadores. Acta Bot. Bras.v.26 (2),p. 435-443.

WEITZMAN, A. L. 2005. Bonnetiaceae, In: J.A. Steyermark, P.E Berry, K Yatskievych \& BK Holst. Flora of the Venezuelan Guayana, Vol (9): Rutaceae ñ Zygophyllaceae. St. Louis: Missouri Botanical Garden Press: 313-324. 